\title{
Hemodiyaliz Hastalarında Görülen Semptom Kümelerinin Cinsel İşlev ile İlişkisi
}

\section{Relationship Between Symptom Clusters and Sexual Function in Hemodialysis Patients}

\author{
Seçil TAYLAN ${ }^{1}$, İlknur ÖZKAN ${ }^{2}$
}

${ }^{I}$ Dr. Öğr. Üyesi, Akdeniz Üniversitesi, Kumluca Sağlık Bilimleri Fakültesi, Hemşirelik Bölümü, Cerrahi Hastalıklar Hemşireliği AD, Antalya, Türkiye

${ }^{2}$ Dr. Öğr. Üyesi, Akdeniz Üniversitesi, Kumluca Să̆lık Bilimleri Fakültesi, Hemşirelik Bölümü, İç Hastalıkları Hemşireliği AD, Antalya, Türkiye

Geliş Tarihi: 23 Nisan 2020

Kabul Tarihi: 21 May1s 2020

\section{İletişim / Correspondence:}

Seçil TAYLAN

E-posta: taylansecil@gmail.com
Özet

Amaç: Bu çalışma, hemodiyaliz hastalarında görülen semptom kümelerinin cinsel işlev ile ilişkisini değerlendirmek amacıyla yapılmıştır.

Gereç ve Yöntem: Aynı ildeki iki devlet hastanesinin diyaliz merkezlerinde hemodiyaliz tedavisi alan 116 hasta ile yapılan çalışma, tanımlayıcı-ilişkisel tiptedir. Araştırmanın verileri, Tanıtıcı Bilgi Formu, Diyaliz Semptom İndeksi ve Arizona Cinsel Yaşantılar Ölçeği ile elde edilmiştir. Hemodiyaliz hastalarının cinsel işlev bozukluğunu etkileyen belirleyicilerin ilişkisini değerlendirmek için tanımlayıcı istatistikler, faktör analizi ve Lineer regresyon analizi yapılmıştır.

Bulgular: Hastaların \%95'inde cinsel işlev bozukluğu olduğu belirlenmiştir. Hastalarda görülen semptom kümelerinin belirlenmesi için yapılan faktör analizinde semptomlar sekiz küme altında toplanmıştır. İkinci semptom kümesi (uykuya dalmada zorluk, uykuyu sürdürmede zorlanma, rahatsız hissetme, nefes darlığı) semptomlarını yaşama ve hala sigara kullanma ile cinsel işlev yetersizliğinin ilişkisi olduğu belirlenmiştir.

Sonuç: Hastaların tamamına yakınında cinsel işlev bozukluğu olduğu ve semptom yönetiminde destekleyici yöntemlere gereksinimleri olduğu belirlenmiştir. Ayrıca, uykusuzluk, nefes darlığı, rahatsızlık hissi semptomlarının cinsel işlev bozukluğu ile ilişkili olduğu sonucuna ulaşılmıştır.

Anahtar kelimeler: Hemodiyaliz; Semptom Kümesi; Cinsel İşlev Bozukluğu.

\section{Abstract}

Objective: This study was conducted to evaluate the relationship between symptom clusters and sexual function seen in hemodialysis patients.

Material and Method: The study conducted with 117 patients who received hemodialysis treatment in the dialysis center of two state hospitals is descriptiverelational. The data of the study were obtained through the Descriptive Characteristic Form, Dialysis Symptom Index, and Arizona Sexual Experience Scale (ACYÖ). Descriptive statistics, factor analysis, and Linear regression analysis were performed to evaluate the relationship of the determinants affecting sexual dysfunction in hemodialysis patients.

Results: It was determined that $95.1 \%$ of the patients had sexual dysfunction. In the factor analysis performed to determine the symptom clusters seen in the patients, the symptoms were collected under 8 clusters. II. It has been determined that there is a relationship between the symptoms cluster (difficulty falling asleep, difficulty in maintaining sleep, feeling uncomfortable, shortness of breath) and still smoking and sexual dysfunction 
Conclusion: It was determined that almost all of the patients had sexual dysfunction and they needed supportive methods in symptom management. Also, it was concluded that the symptoms of insomnia, shortness of breath, discomfort are associated with sexual dysfunction.

Keywords: Hemodialysis; Symptom; Symptom Cluster; Sexual Dysfunction.

\section{GİRIŞ̧}

Kronik böbrek yetmezliği (KBY), böbrek işlevinin ilerleyici şekilde, geriye dönüşü olmaksızın kaybedilmesidir (1). Böbrek yetmezliği hastaları, dünya nüfusunun \%10'undan daha fazlasinı oluşturmaktadır. Hastalık prevalansı ise sabit bir oranda artmaya devam etmektedir (2). Hemodiyaliz, bu hastalığın tedavi yöntemlerinden biridir. Fiziksel ve psikososyal olarak hastalar üzerinde önemli bir etkiye sahip olan hemodiyaliz, yeni bir yaşam tarzıdır. Bu yaşam tarzına uyum sürecinde sosyal aktivitelere katılmak, çalışma hayatı, aile içi ve arkadaşlarla ilişkileri sürdürmek bazı hastalar için son derece zor olabilir ve bu zorlanma süreci çok uzun sürebilir (3). Hastalar kendilerini eksik, tıbbi bakıma bağımlı ve hemodiyaliz sürecinin bir parçası olarak yorgun hissedebilirler (4). Bununla birlikte KBY hastaları sıv1-diyet kısıtlaması, ilaç, sık hastalık, anksiyete, depresyon ve cinsel işlev bozukluğu gibi bir takım sorunlar yaşayabilirler $(5,6)$. Sağlıklı bir yaşam tarzının vazgeçilmez bir parçası ve temel bir insan hak ve gereksinimi olan cinsellik (7), KBY olan hastalarda önemli ölçüde etkilenebilir (8). Cinsel işlev bozukluğu, kronik böbrek yetmezliği olan hastalarda oldukça yaygın görülen bir komplikasyondur. Cinsel işlev bozukluklarının kökeninde organik ve psikolojik nedenler yer almaktadır (9). Diyaliz haslarında meydana gelen endokrin değișiklikler, psikososyal faktörler ve depresyon çeşitli oranlarda cinsel işlevleri bozmaktadır (10). Ayrıca asteni, anemi, üremi, sıklıkla kullanılan antihipertansif tedaviler, yorgunluk gibi çeşitli faktörlerin de cinsel ișlev bozukluğuna neden olduğu bildirilmektedir (6). Yapılan çalışmalarda erkeklerde hemodiyaliz tedavisi alan hastaların tamamina yakınında (\%86) libidoda azalma, cinsel ilişki sırasında gecikmiş veya yetersiz boşalma, oligospermi ve sperm hareketliliğinde azalma, anor- gasmi, cinsel istek ve tatmin azalması sorunlarının oldukça yaygın olduğu tespit edilmiştir (11). Kadın hastalarla yapılan çalışmalarda ise, cinsel şikayetlerin nüfusun geri kalanına göre iki kat daha yüksek olduğu belirtilmiştir (12). KBY'li kadınlarda, cinsel ilişki sırasında istekte azalma, vajinal kuruluk, memnuniyetsizlik ve ağrıda artış olduğu bildirilmiştir (13).

Cinsel işlev bozukluğu böbrek yetmezliği olan hastalarda en önemli stres faktörlerinden biri olmasına rağmen, klinik uygulamalarda ve araştırmalarda, hemodiyaliz hastalarında çok sınırlı bir şekilde ele alınmıştır (14). Buna ek olarak, hemodiyaliz hastaları tarafindan en sik deneyimlenen semptomlar arasında yorgunluk, ağr1, kas krampları, bulantı, kusma, konstipasyon, diyare, kaşıntı, deride kuruluk, uyku bozukluklar1, emosyonel ve cinsel sorunlar yer almaktadır (15-17). Bu semptomların siklığ ve şiddeti her hastada bireysel farklılıklar göstermektedir (15, 18-22).

Hemodiyaliz hastalarının \%35-50'sinin dört ile on semptom, \%25-35'inin onun üzerinde semptom yaşadığ1 belirlenmiştir (23). Yapılan bir çalışmada da ilerlemiş son dönem böbrek yetmezliğinde görülen onbir semptomun, dört kronik hastalık olan kronik obstrüktif akciğer

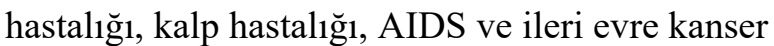
hastalarındaki kadar yaygın olduğu belirtilmiştir (17). Ne yazık ki kanser hastalarının yaşadığı semptomlarla benzerlik göstermesine rağmen, hemodiyaliz hastalarının yaşadıkları semptomlar kanser hastalarındaki kadar erken fark edilememektedir $(17,19,22)$. Semptom yönetimi multidisipliner bir yaklaşım gerektirir. Ayrıca yaşanılan bu semptomların cinsel işlevi nasıl etkilediği ve sağlik profesyonellerinin özellikle hemodiyaliz hastaları ile en çok vakit geçiren meslek grubu olan hemşirelerin bu durumun farkında 
olmas1 önemlidir. Hemodiyaliz hastalarında semptom kümelerinin cinsel işlev ile ilişkisini inceleyen çalışma sayısı yetersizdir. Aynı zamanda sağlı profesyonellerinin hemodiyaliz hastalarının yaşadığı cinsel işlevle ilgili sorunların farkında olması, bireylerin cinsel işlevlerini dikkatlice değerlendirmesi önemlidir. Hastalara bu sorunları yaşamasının normal bir durum olduğu ve birçok hemodiyaliz hastasının bu sorunları yaşadığ bilgisinin verilmesi, konuşulmas1 zor olan bir konuda hasta ile konuşarak yalnız olmadığı duygusunun hissettirilmesi ve her türlü sorununda desteklendiği düşüncesinin hastaya yansıtılması hemşirelik bakımı için önemlidir. Sorunun farkında olmak, uygun tedavi ve bakımın ilk ve en önemli basamağıdır.

\section{GEREÇ VE YÖNTEM}

\subsection{Amaç}

$\mathrm{Bu}$ çalışma, hemodiyaliz hastalarında görülen semptom kümelerinin cinsel işlev ile ilişkisini değerlendirmek amacıyla yapılmıştır.

\subsection{Evren ve Örneklem}

Araştırma aynı ildeki iki devlet hastanesinin diyaliz merkezlerinde hemodiyaliz tedavisi alan hastalar ile yapılmıştır. Örneklem seçimi yapılmadan çalışmaya katılmayı kabul eden, 18 yaş ve üzeri en az altı aydır hemodiyaliz tedavisi gören, evli ya da cinsel partneri olan ve herhangi bir iletişim sorunu olmayan hastalar araștırmaya dahil edilmiştir. Psikiyatrik hastalık tanısı olan ve psikiyatrik ilaç kullanan hastalar çalışmaya dahil edilmemiştir. Çalışmada evrenin (N:124) \%93.5'ine $(\mathrm{n}=116)$ ulaşılmıştır. Sekiz hasta cinsel partneri olmadığı için çalışmaya alınmamıştır.

\subsection{Veri Toplama Araçları ve Özellikleri}

Araştırmanın verileri, Tanıtıcı Bilgi Formu, Diyaliz Semptom İndeksi ve Arizona Cinsel Yaşantılar Ölçeği (ACYÖ) ile elde edilmiştir. Veriler, araştırmacılar tarafindan hastalar hemodiyaliz tedavisi alırken gerekli açıklamalar yapıldıktan sonra yüz yüze görüşme yöntemi ile toplanmıştır. Görüşmeler sırasında yatak başlarındaki perdeler çekilerek hastaların mahremiyet- leri sağlanmıştır. Ayrıca yataklar arası mesafenin hastaları rahatsız etmeyecek uzaklıkta olmasina dikkat edilmiştir. Formların doldurulması yaklaşı 15-20 dakika sürmüştür.

\section{Tanitıcı Bilgi Formu}

$\mathrm{Bu}$ form, literatür incelenerek $(18,20,21,24,25)$ araştırmacılar tarafından hazırlanmıştır. Sosyodemografik özellikler bilgi formu; hemodiyaliz hastalarının tanıtıcı özelliklerini içeren on soru ve hastalık özgeçmişleri ile ilgili altı sorudan oluşmaktadır.

\section{Arizona Cinsel Yaşantılar Ölçeği (ACYÖ)}

Arizona Cinsel Yaşantılar Ölçeği, cinsel işlevin beş temel bileşenini değerlendirmek için tasarlanmıştır. $\mathrm{Bu}$ bileşenler uyarılma, cinsel dürtü, vajinal yağlanma/penil ereksiyon, orgazma ulaşma yeteneği ve orgazmdan memnuniyettir. Ölçeğin Türkçe versiyonunun geçerlik ve güvenirlik çalışması Soykan tarafindan yapılmıştır (26). ACYÖ'nün Cronbach alfa güvenirlik katsayıları erkek ve kadınlarda 0.89 ve 0.90 'dır. ACYÖ'nün erkek ve kadın versiyonları, vajinal yağlama/ penil ereksiyon maddesi açısından birbirinden farklıdır. Beş maddeden oluşan ölçek altılı Likert ölçeğinde derecelendirilmiştir. Ölçekten alınacak puanlar 5 ile 30 arasında değişmekte, daha yüksek puanlar daha fazla cinsel işlev bozukluğunu göstermektedir. Soykan'a göre $\geq 11$ puanları cinsel işlev bozukluğunun kesme noktasıdır. $\mathrm{Bu}$ kesme noktasının üzeri cinsel işlev bozukluğu olarak değerlendirilmektedir (26). Bu çalışmada ölçeğin Cronbach alfa güvenirlik katsayısı kadın ve erkeklerde 0.88 ve 0.89 olarak belirlenmiştir.

\section{Diyaliz Semptom Índeksi (DSi)}

Diyaliz Semptom İndeksi; Weisbord ve ark. (2004) tarafindan, fiziksel ve duygusal semptomları ve bunların şiddetini değerlendirmek amacyyla geliştirilmiştir (27). DSI her biri belirli bir fiziksel ya da duygusal belirtiyi hedefleyen 30 semptom içerir. Son yedi gün içerisinde yaşanan semptomlar evet-hayır olarak cevaplanıp, eğer evet ise bu semptomun ne kadar etkilediği, 5'li likert olarak 1=hiç, $2=$ biraz, 3=bazen, 4=çok az, $5=$ çok fazla şeklinde değerlendirilmektedir. Başka bir deyişle puanın yükselmesi, yaşanan 
semptom şiddetinin arttığını göstermektedir. Cevaplara verilen toplam puanların 150 puana doğru artış göstermesi sözü geçen semptomun etkisinin yükseldiğini göstermektedir. Türkçe DSİ'nin uyarlanması ve güvenirlik ve geçerliliği Önsöz ve Usta Yeşilbalkan (2013) tarafindan yapılmış olup Cronbach alfa katsayısı 0,83 olarak belirlenmiştir (28). Bu çalışmada cronbach alfa 0,81 olarak belirlenmiştir.

\subsection{Verilerin Değerlendirilmesi}

Çalışmada elde edilen bulguların istatistiksel analizleri için. SPSS 21.0 İstatistik paket programı kullanılmıştır. Çalışma verileri değerlendirilirken tanımlayıc1 istatistiksel metotlardan yararlanılmıştır. Sayısal verilerin hesaplanmasında ortalama ve standart sapma, kategorik verilerin hesaplanmasında frekans ve yüzde hesaplamaları kullanılmıştır. İstatistiksel olarak semptom kümelerinin tipleri ve sayılarını belirlemede faktör analizi yöntemi kullanılmıştır. Hemodiyaliz hastalarının cinsel işlev bozukluğunu etkileyen belirleyicilerin ilişkisini değerlendirmek için Lineer regresyon yapılmıştır. Sonuçlar \%95 güven aralığında ve $\mathrm{p}<0.05$ anlamlılık düzeyinde değerlendirilmiştir.

\subsection{Araştırma Etiği}

Araştırmaya başlamadan önce Akdeniz Üniversitesi Tıp Fakültesi Klinik Araştırmalar Etik Kurulu'ndan (06.11.2019; Karar No:1036) onay ve araştırmanın yapıldı ğı kurumdan yazılı izin alınmıştır. Araştırmaya katılmayı kabul eden bireylerden bilgilendirilmiş onam alınmıştır.

\section{BULGULAR}

\subsection{Tanıtıcı Özellikler}

Çalışmada hemodiyaliz tedavisi alan hastaların yaş ortalamasının $58.91 \pm 10.50 \mathrm{y} 11, \% 67.2$ 'sinin erkek, \%69.8'inin ilköğretim mezunu, \%82.8'inin evli, \%93.1'inin çalışmadığı, \%66.4'ünün ilçede yaşadığ1 belirlenmiştir. Hastaların \%44.4'ünün geçmişte \%14'ünün halen sigara kullandığı, \%18.8'inin geçmişte \%5.1'inin halen alkol kullandığı belirlenmiştir.

\subsection{Hastalık ve Hemodiyaliz ile ilgili özellikler}

Hastaların \%37.1'inde diyabetik nefropati nedeniyle hemodiyalize başlandığı, \%44.8'inin kalp ilaçları kullandığ olduğu, \%40.5'inin hemodiyaliz sırasında en çok hipotansiyon semptomunu yaşadığ $1, \% 58.6$ 'sının hemşireden eğitim aldığı ancak \%22.4'ünün hiçbir eğitim almadı̆̆ $1, \% 53.8$ 'inin beş yıldan daha az süredir hemodiyaliz tedavisi aldığ belirlendi (Tablo 2).

\subsection{Oluşan semptom kümeleri ve faktör yüklerinin dağılımı}

Faktör analizi, altta yatan ortaklıkları arayan değişkenler arasında ilişkileri ve çok sayıda semptomlardan anlamlı grupları tahmin etmede kullanılan bir analizdir. Faktör analizinden önce, örneklemenin yeterli olup olmadığını ve faktör korelasyon matrisinin uygun olup olmadığını değerlendirmek için bir KMO örnekleme yeterlilik testi ve Bartlett'in küresellik testi yapıldı. KMO sonucu 0.681 ve Bartlett'in test sonucu 949.605 $(P=.000)$ idi ve bu da örneklem büyüklüğünün faktör analizi için yeterince büyük olduğunu gösterdi. Küme sayısını belirlemek için Açıklayıcı Faktör Analizi yapıldı. Analizde, DSİ'deki semptomların öz değeri 1.00'ın üzerinde olan yedi küme oluştu. Oluşan kümelerin kümülatif değişkenlik yüzdesi (Varyans açıklama yüzdesi) \%66.073 olarak bulundu. Bulant1, bacaklarda şişlik, ayaklarda uyuşukluk ve karıncalanma, ağız kuruluğu, baş ağrısı, kas ağrısı, konsantre olmada zorluk, göğüs ağrısı olmak üzere sekiz semptom bu kümelerden herhangi birinin içinde yer almadı. Birinci kümede üzgün hissetme, sinirli hissetme, endişelenme, kaygılı hissetme şeklinde dört psikolojik semptomun yer aldığı, ikinci kümede uykuya dalmada zorluk, uykuyu sürdürmede zorlanma, rahatsız hissetme, nefes darlığ 1 semptomlarının yer aldığ belirlendi. Üçüncü kümede cinsel ilişkide ilgide azalma, cinsel doyum almada azalma; dördüncü kümede kabızlık, kusma, öksürme, beşinci kümede deride kuruluk, kaşınt1, sersemlik, baş dönmesi, altıncı kümede ishal ve iştahta azalma; yedinci kümede ise bacaklar1 hareketsiz tutmada zorlanma ile kas krampları semptomlarının yer aldığı belirlendi (Tablo 3). 
Taylan ve Özkan; Hemodiyalizde Semptom Kümeleri ve Cinsel İşlev

Tablo 1. Hastaların Tanıtıcı Özellikleri

\begin{tabular}{|c|c|c|c|}
\hline Tanıtıcı Özellikler & & $\mathrm{n}(116)$ & $\%(100)$ \\
\hline Cinsiyet & $\begin{array}{l}\text { Kadın } \\
\text { Erkek }\end{array}$ & $\begin{array}{l}38 \\
78\end{array}$ & $\begin{array}{l}32.8 \\
67.2\end{array}$ \\
\hline Yaş & Yaş ortalama (yıl) & \multicolumn{2}{|c|}{$58.91 \pm 10.50$} \\
\hline Eğitim & $\begin{array}{l}\text { Okur-yazar değil } \\
\text { Okur-yazar } \\
\text { İlköğretim } \\
\text { Ortaöğretim } \\
\text { Üniversite }\end{array}$ & $\begin{array}{c}15 \\
10 \\
81 \\
7 \\
3\end{array}$ & $\begin{array}{c}12,9 \\
8,6 \\
69,8 \\
6,0 \\
2,6\end{array}$ \\
\hline Medeni Durum & $\begin{array}{l}\text { Evli } \\
\text { Bekâr }\end{array}$ & $\begin{array}{l}96 \\
20\end{array}$ & $\begin{array}{l}82,8 \\
17,2\end{array}$ \\
\hline Çalışma durumu & $\begin{array}{l}\text { Çalışıyor } \\
\text { Çalışmıyor }\end{array}$ & $\begin{array}{c}8 \\
108 \\
\end{array}$ & $\begin{array}{c}6,9 \\
93,1\end{array}$ \\
\hline Yaşanılan Yer & $\begin{array}{l}\text { İl } \\
\text { İlçe } \\
\text { Köy }\end{array}$ & $\begin{array}{c}7 \\
77 \\
32\end{array}$ & $\begin{array}{c}6,0 \\
66,4 \\
27,6\end{array}$ \\
\hline Sigara içme öyküsü (Diyaliz tedavisi öncesi) & $\begin{array}{l}\text { Evet } \\
\text { Hayır }\end{array}$ & $\begin{array}{l}51 \\
65\end{array}$ & $\begin{array}{l}44,4 \\
55,6\end{array}$ \\
\hline Şu an sigara içme & $\begin{array}{l}\text { Evet } \\
\text { Hayır }\end{array}$ & $\begin{array}{c}14 \\
102 \\
\end{array}$ & $\begin{array}{l}12.0 \\
88.0\end{array}$ \\
\hline Alkol içme öyküsü (Diyaliz tedavisi öncesi) & $\begin{array}{l}\text { Evet } \\
\text { Hayır }\end{array}$ & $\begin{array}{l}22 \\
94\end{array}$ & $\begin{array}{l}18.8 \\
81.2\end{array}$ \\
\hline Şu an alkol içme & $\begin{array}{l}\text { Evet } \\
\text { Hayır }\end{array}$ & $\begin{array}{c}6 \\
110\end{array}$ & $\begin{array}{c}5.1 \\
94.9\end{array}$ \\
\hline
\end{tabular}

Tablo 2. Hastaların Hastalık ve Hemodiyaliz tedavisine ilişkin Özellikleri

\begin{tabular}{|c|c|c|c|}
\hline \multicolumn{2}{|c|}{ Tanıtıcı Özellikler } & \multirow[b]{2}{*}{$\begin{array}{c}\mathrm{n}(116) \\
17 \\
36 \\
3 \\
43 \\
17 \\
\end{array}$} & \multirow[b]{2}{*}{$\begin{array}{c}\%(100) \\
14,7 \\
31,0 \\
2,6 \\
37,1 \\
14,7\end{array}$} \\
\hline İlk Tanı & $\begin{array}{l}\text { Kronik Glomerülonefrit } \\
\text { Hipertansif Böbrek Hastalı̆̆ } 1 \\
\text { Pyelonefrit } \\
\text { Diyabetik Nefropati } \\
\text { Polikistik Böbrek Hastalığ1 }\end{array}$ & & \\
\hline $\begin{array}{l}\text { Hemodiyaliz } \\
\text { dişı ilaç } \\
\text { kullanma } \\
\text { durumu }\end{array}$ & $\begin{array}{l}\text { Yok } \\
\text { Kalp İlaçları } \\
\text { İnsülin } \\
\text { Diğer ilaçlar (Antiepileptik İlaç, Bronkodilatör, Antikoagülan Tiroid İlaçları) }\end{array}$ & $\begin{array}{c}42 \\
52 \\
15 \\
7\end{array}$ & $\begin{array}{c}36,2 \\
44,8 \\
12.9 \\
6.1\end{array}$ \\
\hline $\begin{array}{l}\text { Ek Hastalık } \\
\text { Varlığ } 1\end{array}$ & $\begin{array}{l}\text { Var } \\
\text { Yok }\end{array}$ & $\begin{array}{l}78 \\
38 \\
\end{array}$ & \\
\hline $\begin{array}{l}\text { Hemodiyaliz } \\
\text { sırasında en } \\
\text { çok yaşanılan } \\
\text { sorunlar }\end{array}$ & $\begin{array}{l}\text { Hipotansiyon } \\
\text { Bulantı kusma } \\
\text { Kramp } \\
\text { Halsiz hissetme } \\
\text { Rahatsı ve üzgün hissetme }\end{array}$ & $\begin{array}{l}47 \\
16 \\
35 \\
17 \\
1\end{array}$ & $\begin{array}{c}40,5 \\
13,8 \\
30,2 \\
14,7 \\
, 9\end{array}$ \\
\hline Eğitim Alma & $\begin{array}{l}\text { Hayır } \\
\text { Evet hemşire } \\
\text { Evet Hekim }\end{array}$ & $\begin{array}{l}26 \\
68 \\
22 \\
\end{array}$ & $\begin{array}{l}22,4 \\
58,6 \\
19,0\end{array}$ \\
\hline $\begin{array}{l}\text { Diyaliz Yilı } \\
5.78 \pm 5.07\end{array}$ & $\begin{array}{l}<5 \text { years } \\
5-10 \text { years } \\
>10 \text { years }\end{array}$ & $\begin{array}{l}63 \\
31 \\
22\end{array}$ & $\begin{array}{l}53,8 \\
27,4 \\
18,8\end{array}$ \\
\hline
\end{tabular}




\subsection{Cinsel İşlev Bozukluğu yaşama durumları}

Hemodiyaliz hastalarının \%91.5'inin cinsel işlev bozukluğu yaşadığı ve Arizona Cinsel Deneyim Ölçeği puan ortalamasının $20.88 \pm 6.07$ olduğu belirlendi (Tablo 4).

\subsection{Cinsel İşlev Bozukluğu Belirleyicilerinin Stepwise Multiple Linear Regression Model ile İncelenmesi}

Araştırmada hastaların cinsel işlev bozukluğunun yordamasında tek değişkenli analizlerde istatistiksel olarak anlamlı farklılık saptanan değişkenler ve faktör analizi ile oluşturulan semptom kümeleri Stepwise Multiple Linear Regression analizi ile değerlendirilmiştir. ACYÖ puanında en iyi model ikinci adımda oluşmuştur (Table 5). ACYÖ için Durbin- Watson değeri model geçerliliğ̈ini sağlamıştır $(\mathrm{D}=1.916)$. Tolerans ve VIF değerleri, değişkenlerin eşitliğinin bulunmadığını göstermiştir. ACYÖ standart sapmasını ikinci semptom kümesi standart sapmasındaki bir birimlik artışın 0.249 birim arttırdığı saptanmıştır. Tanımlayıcı özelliklerden ise halen sigara içenlerin içmeyenlere göre ACYÖ puanını 0.179 birim arttığ belirlenmiştir. Oluşturulan son modelin varyansın \%8.3'ünü açıkladığı belirlenmiştir $(\mathrm{p}=0.000$; Tablo 5).

Tablo 3. Hemodiyaliz hastalarında görülen semptom kümeleri ve faktör yükleri

\begin{tabular}{|c|c|c|c|c|c|c|c|}
\hline Semptomlar & $\begin{array}{c}\text { I. } \\
\text { Küme }\end{array}$ & $\begin{array}{c}\text { II. } \\
\text { Küme }\end{array}$ & $\begin{array}{c}\text { III. } \\
\text { Küme }\end{array}$ & $\begin{array}{l}\text { IV. } \\
\text { Küme }\end{array}$ & $\begin{array}{c}\mathrm{V} . \\
\text { Küme }\end{array}$ & $\begin{array}{c}\text { VI. } \\
\text { Küme }\end{array}$ & $\begin{array}{l}\text { VII. } \\
\text { Küme }\end{array}$ \\
\hline $\begin{array}{l}\text { Üzgün hissetme } \\
\text { Sinirli hissetme } \\
\text { Endişelenme } \\
\text { Kaygıll hissetme }\end{array}$ & $\begin{array}{l}, 883 \\
, 797 \\
, 767 \\
, 759\end{array}$ & & & & & & \\
\hline $\begin{array}{l}\text { Uykuya dalmada zorluk } \\
\text { Uykuyu Sürdürmede Zorlanma } \\
\text { Rahatsız hissetme } \\
\text { Nefes darlığ1 }\end{array}$ & & $\begin{array}{l}, 891 \\
, 884 \\
, 687 \\
, 408 \\
\end{array}$ & & & & & \\
\hline $\begin{array}{l}\text { Cinsel ilişkide ilgide azalma } \\
\text { Cinsel doyum almada azalma }\end{array}$ & & & $\begin{array}{l}, 962 \\
, 962 \\
\end{array}$ & & & & \\
\hline $\begin{array}{l}\text { Kabızlık } \\
\text { Kusma } \\
\text { Öksürme }\end{array}$ & & & & $\begin{array}{l}, 686 \\
, 681 \\
, 657 \\
\end{array}$ & & & \\
\hline $\begin{array}{l}\text { Deride kuruluk Kaşıntı } \\
\text { Sersemlik } \\
\text { Başdönmesi }\end{array}$ & & & & & $\begin{array}{l}, 727 \\
, 708 \\
, 488 \\
, 454\end{array}$ & & \\
\hline $\begin{array}{l}\text { İshal } \\
\text { İştahta azalma }\end{array}$ & & & & & & $\begin{array}{l}, 760 \\
, 640 \\
\end{array}$ & \\
\hline $\begin{array}{l}\text { Bacakları hareketsiz tutmada } \\
\text { zorlanma } \\
\text { Kas krampları }\end{array}$ & & & & & & & $\begin{array}{l}, 826 \\
, 568\end{array}$ \\
\hline
\end{tabular}

Tablo 4. Hastaların Cinsel İşlev Bozukluğu yaşama durumları

\begin{tabular}{|l|l|l|l|}
\cline { 3 - 4 } \multicolumn{2}{c|}{} & $\boldsymbol{n}$ & $\%$ \\
\hline Cinsel işlev Bozukluğu & Evet & 107 & 91,5 \\
& Hayır & 10 & 8,5 \\
\hline ACYÖ & Ortalama \pm SS (Min-Max) & $20.88 \pm 6.07(9-30)$ \\
\hline
\end{tabular}


Tablo 5. Semptom kümeleri ile cinsel işlev bozukluğu arasındaki arasındaki ilişkinin Lineer Regresyon ile incelenmesi

\begin{tabular}{|c|c|c|c|c|c|c|c|c|c|}
\hline \multirow{9}{*}{ 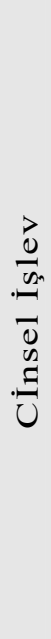 } & \multirow[b]{2}{*}{ Model } & \multirow[b]{2}{*}{$\mathrm{R}$} & \multirow[b]{2}{*}{$\mathrm{R}^{2}$} & \multirow[b]{2}{*}{$\begin{array}{c}\text { Düzeltilmiş } \\
\mathrm{R}^{2}\end{array}$} & \multicolumn{4}{|c|}{ Değişim istatistikleri } & \multirow[b]{2}{*}{$\begin{array}{l}\text { Durbin- } \\
\text { Watson }\end{array}$} \\
\hline & & & & & $\begin{array}{c}\text { Standart tahmin } \\
\text { hatas1 }\end{array}$ & R2 Değişimi & F Değişimi & $\begin{array}{l}\text { F değişim } \\
\mathrm{p}\end{array}$ & \\
\hline & 1 &, 258 &, 067 &, 058 & 5,84713 &, 067 & 8,195 &, 005 & \\
\hline & 2 &, 314 & ,099 &, 083 & 5,77102 &, 032 & 4,053 & ,046 & 1.916 \\
\hline & \multirow{2}{*}{\multicolumn{2}{|c|}{ Model 2}} & \multicolumn{2}{|c|}{$\begin{array}{l}\text { Standartlaşmamış } \\
\text { Katsayılar }\end{array}$} & $\begin{array}{c}\text { Standart } \\
\text { Katsayılar }\end{array}$ & & & \multicolumn{2}{|c|}{$\begin{array}{l}\text { Eşitlik/ortaklık } \\
\text { istatistikleri }\end{array}$} \\
\hline & & & $\mathrm{B}$ & $\mathrm{SH}$ & Beta & $\mathrm{t}$ & $\mathrm{p}$ & Tolerance & VIF \\
\hline & & & 16,399 & 1,613 & & 10,170 &, 000 & & \\
\hline & $\begin{array}{l}\text { II. Sem } \\
\text { Kümesi }\end{array}$ & & 1,023 &, 366 & ,249 & 2,794 &, 006 & ,997 & 1,003 \\
\hline & $\begin{array}{l}\text { Sigara i } \\
\text { (Şu an/ }\end{array}$ & & 3,314 & 1,646 &, 179 & 2,013 &, 046 & ,997 & 1,003 \\
\hline
\end{tabular}

\section{TARTIŞMA}

Hemodiyaliz hastalarında pek çok semptom yaygın görülse de sağlık profesyonelleri tarafından fark edilememekte ve hastanın yaşam kalitesi düşmektedir (Bossola ve ark., 2019; D’Onofrio ve ark., 2017). Etkin semptom yönetimin sağlanması açısından hemodiyaliz hastalarında görülen fiziksel ve duygusal semptomların değerlendirilmesi önemlidir. Çalışmada hemodiyaliz hastalarında görülen semptom kümeleri belirlenmiş ve semptomların cinsel işlev ile olan ilişkisi değerlendirilmiştir.

Hemodiyaliz hastalarında görülen semptomlar yedi kümede toplanmıştır. Literatürde semptom kümeleri ile ilgili yapılan çalışmalarda farklı semptomların farklı sayıda semptom kümesi altında toplandığ görülmektedir (29-32). Ayrıca küme analizi yapılmayan çalışmalarda da hastalarda görülen semptomların çeşitlilik gösterdiğine dikkat çekilmektedir $(20,22,33)$. Örneğin bir çalışmada hastalarda görülen semptomlar enerji (yorgunluk, uykusuzluk ve kas güçsüzlüğü), kardiyak problemler (nefes darlığı, göğüs ağrıs1), ağr1/rahatsızlık (kas ağrısı, baş ağrısı ve kaşıntı) ve gastrointestinal sistem (karın ağrısı, bulantı-kusma ve kramplar) şeklinde gruplanmıştır (29). Başka bir çalışmada semptom kümeleri birinci grupta üremi sendromunun genel semptomları nefes darlığı, baş dönmesi, iştahsızlık; ikinci grup nöromüsküler problemler kas ağrısı, göğüs ağrısı ve el/ayaklarda uyuşma; üçüncü grup ise cilt problemleri olup cilt kuruluğu ve kaşıntı olarak belirtilmiştir (31). Bu çeşitliliğin nedeni kronik böbrek yetmezliğine eşlik eden hastalıklar, kullanılan ilaçlar, hemodiyaliz tedavisinin yönetimi, diyete uyum ya da uyumsuzluk gibi yaşamı etkileyen durumların da çeşitlilik göstermesi olabilir. Aslında bu sonuçlar, hemodiyaliz hastalarında görülen semptomların yönetiminin oldukça zor ve maalesef yetersiz olduğu anlamına da gelebilir.

Diyaliz hastalarının cinsel yaşamları çok fazla konuşulmayan ve ihmal edilen konulardan biridir. Çalışmada diyaliz hastalarının neredeyse tamamına yakınının (\%91.5) cinsel işlev bozukluğu yaşadığı ve Arizona Cinsel Deneyim Ölçeği puan ortalamasının oldukça yüksek olduğu bulunmuştur. Türkiye'de yapılan bir çalışmada, çalışma bulgularına benzer olarak diyaliz hastalarının \%85.6'sında cinsel işlev bozukluğu tespit edilmiştir (34). Literatürde çalışma bulgularını destekleyen yüksek düzeyde cinsel işlev bozukluğuna dikkat çeken çalışmalar bulunmaktadır $(8,35,36)$. Cinsel işlev bozukluğunun bu derece yüksek düzeyde olması aslında bu hasta grubunda bu konunun daha yüksek farkındalığı ve önemsenmeyi hak ettiği anlamına gelmektedir. Başka bir deyişle cinsel işlev bozukluğu, sağlık profesyonelleri tarafından önemli bir sağl1k sorunu olarak ele alınmalıdır. 
Hastalarda görülen cinsel işlev bozukluğunun yordayıc1ları lineer regresyon analizi ile değerlendirildiğinde, ikinci semptom kümesindeki semptomların varlığının ve halen sigara içme durumunun cinsel işlev bozukluğunu arttırdığ 1 belirlenmiştir. Çalışmada ikinci semptom kümesinde yer alan uykuyu sürdürmede zorluk, uykusuzluk, rahatsız hissetme, nefes darlığı semptomlarının cinsel işlev bozukluğunun yordayıcıları olduğu sonucu çıkmıştır. Bir çalışmada diyaliz hastalarının \%80'inin uykusuzluk sorunu yaşadığı (37), kapsamlı bir derlemede ise, hemodiyaliz hastalarının, kısa, bölünmüş uyku sorunları yaşadığı bildirilmiştir (38). Uykusuzluk, uykuya dalma veya uykuda kalma yetersizliğidir aynı zamanda kötü uyku kalitesi ve kötü yaşam kalitesi ile karakterizedir (39). Nitekim çalışmada, uyku sorununun cinsel işlev yetersizliğinin yordayıcılarından biri olduğu sonucu çıkmıştır. Yang ve arkadaşlarının (2015) diyaliz hastalarında farmakolojik olmayan girişimlerle ilgili 12 randomize kontrollü çalışma ve bir prospektif kohort çalışmasını gözden geçirdiği sistematik derleme çalışmasının sonuçlarından biri Bilişsel Davranışçı Terapi (BDT)'nin uykusuzluk için hemodiyaliz hastalarında yararlı olduğudur (40). $\mathrm{Bu}$ yöntemin uykusuzluk sorunu yaşayan hastalarda kullanılması için öncelikle bu semptomun ve sonuçlarının farkında olunması oldukça önemlidir.

Rahatsız hissetme semptomu kişinin algıladığı sağl1k durumu ile ilgilidir ayrıca bir kişinin sağlık davranışlarını ve sağlık sorumluluklarını etkiler. Kişinin sağlık durumunu algılaması, gelecekte sağlığını kontrol edebilme ve sağliklı yaşam biçimi davranışlarını da olumlu gösterme inancını olumlu yönde etkiler. Hemodiyaliz hastaları ile yapılan bir çalışmada, cinsel işlev bozukluğu olan katılımcıların algılanan sağlık düzeyleri (rahatsız hissetme) anlamlı düzeyde düşük bulunmuştur (34). Halen sigara içen hastalar, sağlıklı yaşam biçimini sürdürmede yetersiz olan hastalardır.
Çalışmada, hastaların \%12'sinin halen sigara içtiği ve sigara içmenin cinsel işlev bozukluğunu artırdığ1 sonucuna ulaşılmıştır. Literatürde çalışma bulgularına benzer olarak diyaliz hastalarının \%14-15 oranında sigara içtiğine dikkat çekilmektedir $(41,42)$. Nitekim bu hastaların daha fazla nefes darlığ 1 sorunu yaşamaları da beklenilen bir durumdur. Hemodiyaliz, akut olarak: enfeksiyonlara, plevral efüzyonlara ve ARDS'ye neden olur ve kronik olarak: akciğer parankiminin kalsifikasyonuna ve son olarak solunum bozukluğuna yol açar (43). Literatürde diyaliz hastalarının yaşadıkları nefes darlığı sorununun incelendiği çalışmalar oldukça azdır. Cinsel işlevin nefes darlı̆̆ 1 ile ilişkisinin değerlendirildiği bir çalışmaya ise rastlanmamıştır. Özellikle bir çalışmada hemodiyaliz öncesi hastaların tamamının nefes darlığı yaşadığına dikkat çekilmiştir. Ancak spesifik olarak, solunum sistemi ile ilgili semptomların iyi belgelenmediği de bildirilmektedir (43). Çalışma sonucunda sağlıklı yaşam tarzını sürdürme açısından hastaların desteklenmesinin önemi ortaya çıkmaktadır.

$\mathrm{Bu}$ çalışmanın sınırlılıkları; örneklemin küçük olması ve sadece iki hemodiyaliz merkezinde yapılmış olmasıdır. Çalışmanın daha büyük örneklem grubunda yapılması önerilmektedir.

\section{SONUÇ}

Hemodiyaliz hastalarının tamamına yakınında cinsel işlev bozukluğu yaşandığı ve cinsel işlev bozukluğunun uykuyu sürdürmede zorluk, uykusuzluk, nefes darlığ1, rahatsız hissetme semptomlarını yaşayan ve halen sigara içen hastalarda ilişkisel olarak arttığ belirlendi. Sağlık profesyonellerinin özellikle de semptom yönetiminde önemli rolü olan hemşirelerin, hemodiyaliz hastalarının yaşadığ cinsel işlev bozukluğu sorununun ve hastalarda görülen semptomlarla ilişkisinin farkında olması ve yönetmesi önemlidir. 


\section{Kaynaklar}

1. Kara B. One of the priority issues in patients with end - stage renal failure undergoing hemodialysis: Quality of life. TAF Preventive Medicine Bulletin. 2012; 11: 631-8.

2. Eckardt KU, Coresh J, Devuyst O, Johnson RJ, Kottgen A, Levey AS, et al. Evolving importance of kidney disease: from subspecialty to global health burden. Lancet. 2013; 382 (9887): 158-69.

3. Griva K, Davenport A, Harrison M, Newman S. An evaluation of illness, treatment perceptions, and depression in hospital- vs. home-based dialysis modalities. J Psychosom Res. 2010; 69(4): 363-70.

4. Yılmaz Karabulutlu E, Okanlı A. Hemodiyaliz hastalarında hastalık algısının değerlendirilmesi. Anadolu Hemşirelik ve Sağlık Bilimleri Dergisi. 2011; 14(4).

5. Charlot A, deRoux S. Biting through an arteriovenous hemodialysis graft: an unusual method of suicide. J Forensic Sci. 2009; 54(6): 1456-7.

6. Keskin G, Babacan Gumus A, Tasdemir Yigitoglu G. Sexual dysfunctions and related variables with sexual function in patients who undergo dialysis for chronic renal failure. J Clin Nurs. 2019; 28(1-2): 257-69.

7. Woloski-Wruble AC, Oliel Y, Leefsma M, Hochner-Celnikier D. Sexual activities, sexual and life satisfaction, and successful aging in women. J Sex Med. 2010; 7(7): 2401-10.

8. Doss F, Polaschek N. Assessing sexual dysfunction in people living on dialysis in a New Zealand renal service. Ren Soc Aust J. 2012; 8 (3): 104-8.

9. Göriş S, Bilgi N. Son dönem böbrek yetmezliği olan hastalarda cinsel fonksiyon bozukluğu ve hemşirelik bakımı. . Nefroloji Hemşireliği Dergisi. 2015; 10(1): 68-74.

10. Aribi L, Masmoudi R, Ben Houidi A, Charfeddine F, Jarraya F, Hachicha J, et al. [Sexual disorder in hemodialysis patients]. Tunis Med. 2015; 93(2): 79-84.

11. Barroso LV, Miranda EP, Cruz NI, Medeiros MA, Araújo AC, Mota Filho FH, et al. Analysis of sexual function in kidney transplanted men. Transplantation Proceedings Transplantasyon Bildirileri. 2008; 40: 3489-91.

12. Prescott L, Eidemak I, Harrison AP, Molsted S. Sexual dysfunction is more than twice as frequent in Danish female predialysis patients compared to age - and gender - matched healthy controls. International Urology and Nephrology. 2014; 46: 979-84. .

13. Mustafa R, Schmidt RJ. Sexual dysfunction in dialysis patients: A review. . Austin Journal of Nephrology and Hypertension. 2015; 2(1): 1-7.

14. Küçük L, Türkmen A, Küçük M. Sexual dysfunction in women after renal transplantation. . Sex Disabil. 2013; 31: 15566.

15. Amro A, Waldum B, Dammen T, Miaskowski C, Os I. Symptom clusters in patients on dialysis and their association with quality-of-life outcomes. Journal of Renal Care. 2014; 40(1): 23-33.

16. Cabrera V, Hansson J, Kliger A, Finkelstein F. Symptom Management of the Patient with CKD: The Role of Dialysis. Clin J Am Soc Nephrol. 2017; 12(4): 687-93.

17. Solano J, Gomes B, Higginson I. A comparison of symptom prevalence in far advanced cancer, AIDS, heart disease, chronic obstructive pulmonary disease and renal disease. J Pain Symptom Manage. 2006; 31: 58-69.

18. Akgöz N, Arslan S. Examination of Symptoms in Patients Who are on Hemodialysis Treatment. Türk Nefroloji, Diyaliz ve Transplantasyon Hemşireleri Derneği Nefroloji Hemşireliği Dergisi. 2017; 12(1): 20-8.

19. Davison S, Jhangri G, Johnson J. Cross-sectional validity of a modified Edmonton symptom assessment system in dialysis patients: a simple assessment of symptom burden. Kidney Int 2006; 69(9): 1621-5.

20. Göriş S, Ceyhan Ö, Taşcı S, Doğan N. Do Symptoms Related to Hemodialysis Affect Marital Adjustment? Sex Disabil. 2016; 34: 63-73.

21. Hintistan S, Deniz A. Evaluation of Symptoms in Patients Undergoing Hemodialysis. Bezmialem Science. 2018; 6: $112-8$.

22. Raj R, Ahuja K, Frandsen M, Jose M. Symptoms and their recognition in adult haemodialysis patients: Interactions with quality of life. Nephrology. 2017; 22(3): 228-33.

23. Bossola M, Pepe G, Picca A, Calvani R, Marzetti E. Treating symptoms to improve the quality of life in patients on chronic.Hemodialysis.International Urology and Nephrology. 2019; 51: 885-7

24. Daugirdas J. Second generation logarithmic estimates of single-pool variable volume Kt/V: an analysis of error. J Am Soc Nephrol. 1993; 4: 1205.

25. EL-Sheikh M, El Ghazaly G. Assessment of hemodialys adequacy in patients with chronic kidney disease in the hemodialysis unit at Tanta University Hospital in Egypt. Indian J Nephrol. 2016; 26(6): 398-404.

26. Soykan A. The reliability and validity of Arizona sexual experiences scale in Turkish ESRD patients undergoing hemodialysis. . Int J Impot Res. 2004; 16: 531-4. 
27. Weisbord SD, Fried LF, Arnold RM, Fine MJ, Levenson DJ, Peterson RA, et al. Prevalence, severity, and importance of physical and emotional symptoms in chronic hemodialysis patients. J Am Soc Nephrol. 2005; 16(8): 2487-94.

28. Önsöz HB, Usta Yeşilbalkan Ö. Reliability and validity of the turkish version of the dialysis symptom index in chronic hemodialysis patients. . Turkish Nephrology, Dialysis and Transplantation Journal. 2013; 22(1): 60-7.

29. Jablonski A. The multidimensional characteristics of symptoms reported by patients on hemodialysis. Nephrol Nurs J. 2007; 34(1): 29-37.

30. Özdemir C.. Diyaliz Tedavisi alan hastalarda semptom kümelerinin belirlenmesi [Yüksek Lisans]. Ankara: Başkent Üniversitesi; 2011

31. Thong MS, van Dijk S, Noordzij M, Boeschoten EW, Krediet RT, Dekker FW, et al. Symptom clusters in incident dialysis patients: associations with clinical variables and quality of life. Nephrol Dial Transplant. 2009; 24(1): 225-30.

32. Yu IC, Huang JY, Tsai YF. Symptom cluster among hemodialysis patients in Taiwan. Appl Nurs Res. 2012; 25(3): 190-6.

33. Weisbord SD, Bossola M, Fried LF, Giungi S, Tazza L, Palevsky PM, et al. Cultural comparison of symptoms in patients on maintenance hemodialysis. Hemodial Int. 2008; 12(4): 434-40.

34. Sabanciogullari S, Taşkın Yılmaz F, İlke Güngör F, Söylemez S, B. BR. Sexual Function in Patients with Chronic Renal Failure on Hemodialysis and Its Effects on Patients' Perception of Health and Life Satisfaction. Sexuality and Disability. 2015; 33: 185-6.

35. Finkelstein FO, Shirani S, Wuerth D, Finkelstein SH. Therapy Insight: sexual dysfunction in patients with chronic kidney disease. Nat Clin Pract Nephrol. 2007; 3(4): 200-7.

36. Martin-Diaz F, Reig-Ferrer A, Ferrer-Cascales R. [Sexual function and quality of life in hemodialysis male patients]. Nefrologia. 2006; 26(4): 452-60.

37. Hui DS, Wong TY, Ko FW, Li TS, Choy DK, Wong KK, et al. Prevalence of sleep disturbances in chinese patients with end-stage renal failure on continuous ambulatory peritoneal dialysis. Am J Kidney Dis. 2000; 36(4): 783-8.

38. Parker KP, Bliwise DL, Bailey JL, Rye DB. Daytime sleepiness in stable hemodialysis patients. Am J Kidney Dis. 2003; 41(2): 394-402.

39. Novak M, Shapiro CM, Mendelssohn D, Mucsi I. Diagnosis and management of insomnia in dialysis patients. Semin Dial. 2006; 19(1): 25-31.

40. Yang B, Xu J, Xue Q, Wei T, Xu J, Ye C, et al. Non-pharmacological interventions for improving sleep quality in patients on dialysis: systematic review and meta-analysis. Sleep Med Rev. 2015; 23: 68-82.

41. Liebman SE, Lamontagne SP, Huang LS, Messing S, Bushinsky DA. Smoking in dialysis patients: a systematic review and meta-analysis of mortality and cardiovascular morbidity. Am J Kidney Dis. 2011; 58(2): 257-65.

42. Longenecker JC, Coresh J, Klag MJ, Levey AS, Martin AA, Fink NE, et al. Validation of comorbid conditions on the end-stage renal disease medical evidence report: the CHOICE study. Choices for Healthy Outcomes in Caring for ESRD. J Am Soc Nephrol. 2000; 11(3): 520-9.

43. Palamidas AF, Gennimata SA, Karakontaki F, Kaltsakas G, Papantoniou I, Koutsoukou A, et al. Impact of hemodialysis on dyspnea and lung function in end stage kidney disease patients. Biomed Res Int. 2014; 2014: 212751. 